\title{
Dietary calcium and vitamin D intakes in childhood and throughout adulthood and mammographic density in a British
} birth cohort

\author{
G Mishra*,', V McCormack', D Kuh', R Hardy', A Stephen ${ }^{3}$ and I dos Santos Silva ${ }^{2}$ \\ 'MRC Unit for Lifelong Health and Ageing, Department of Epidemiology and Public Health, University College London, London, UK; ${ }^{2}$ Department of \\ Epidemiology and Population Health, London School of Hygiene and Tropical Medicine, London, UK; ${ }^{3}$ MRC Human Nutrition Research, Elsie Widdowson \\ Laboratory, Cambridge, UK
}

\begin{abstract}
We examined the role of dietary calcium and vitamin D intakes in childhood and throughout adulthood in relation to mammographic density using data from a nationally representative cohort of I I 61 women followed up since their birth in 1946. Dietary intakes at the age of 4 years were determined by 24-h recalls and at the ages of 36, 43 and 53 years by 5-day food records. After adjusting for known risk factors and confounders, no evidence of a relationship between dietary calcium or vitamin $D$ intakes and mammographic density approximately at the age of 50 years was found, except for a cross-sectional relationship between dietary calcium intake at the age of 53 years and breast density in women who were post-menopausal at the time of mammography, with those in the top fifth of the distribution of calcium intake having a $0.53 \mathrm{~s}$.d. lower percent breast density than those in the lowest fifth $(P$-value $<0.0$ I for linear trend).

British Journal of Cancer (2008) 99, I539- 1543. doi: I0.I038/sj.bjc.6604697 www.bjcancer.com
\end{abstract}

Published online 30 September 2008

(C) 2008 Cancer Research UK

Keywords: calcium; vitamin D; childhood; mammographic breast density

Some evidence suggests that high intake of vitamin D (or high circulating levels of the status marker 25-hydroxyvitamin D $(25(\mathrm{OH}) \mathrm{D}))$ and/or calcium is associated with a decreased risk of breast cancer (Shin et al, 2002; Cui and Rohan, 2006; Garland et al, 2007; John et al, 2007), although epidemiological findings have so far been inconsistent. Seven studies have also examined intake of calcium and/or vitamin D, as assessed by Food Frequency Questionnaires (FFQ), in relation to mammographic breast density, which is a strong risk factor for breast cancer (McCormack and dos Santos Silva, 2006). Of these studies, one reported a strong inverse relationship for vitamin $\mathrm{D}$ and calcium in both pre- and post-menopausal women (Berube et al, 2004); three showed inverse associations among pre-menopausal but not postmenopausal women (Holmes et al, 2001; Berube et al, 2005; Diorio et al, 2006); a fifth reported no association with $25(\mathrm{OH}) \mathrm{D}$ but found that women with the highest levels of both $25(\mathrm{OH}) \mathrm{D}$ and calcium intakes had the lowest percent density (Knight et al, 2006); and two reported no associations in either group (Vachon et al, 2000; Thomson et al, 2007). All these studies were cross sectional, that is, they relied on a single assessment of calcium and/or vitamin $\mathrm{D}$ intakes close to the time of the mammographic examination. Factors across the life course may increase the risk

*Correspondence: Dr G Mishra, MRC Lifelong Unit for Health and Ageing, Royal Free and University College Medical School, 33 Bedford Place, London WCIB 5JU, UK;

E-mail: g.mishra@nshd.mrc.ac.uk

Received 27 June 2008; revised 5 September 2008; accepted 8 September 2008; published online 30 September 2008 of breast cancer (dos Santos Silva and De Stavola, 2002; dos Santos Silva et al, 2004; Sellers et al, 2007) and thus intakes of calcium and vitamin $\mathrm{D}$ at different ages may correlate differently with mammographic density.

The MRC National Survey of Health and Development (NSHD), a population-based birth cohort study (Wadsworth et al, 2006) provides a unique opportunity to investigate whether calcium and vitamin $\mathrm{D}$ intakes in childhood and throughout adulthood are related to women's breast density in midlife.

\section{MATERIALS AND METHODS}

The Medical MRC NSHD is a British national representative sample of 2815 men and 2547 women followed since their birth in March 1946 (Wadsworth et al, 2006). A wealth of medical and social data has been collected at more than 25 follow-ups by home visits, medical examinations and postal questionnaires. At the age of 4 years, a 24-h maternal recall of all meals consumed was completed for $98 \%$ of the cohort members. Nutrient intakes were calculated using period and age-specific food portion sizes and nutrient database. One of the main sources of vitamin $D$ at the age of 4 years was from a cod liver oil supplement, which was widely available to children under the age of 5 years in post-war Britain (Prynne et al, 2002). However, as insufficient information on its uptake was available, vitamin D intakes could not be determined accurately. At the ages of 36, 43 and 53 years, all food and drink consumed both at home and away were recorded in 5-day food diaries using household measures and estimating portion sizes according to the detailed guidance notes and photographs 
provided at the beginning of the diary. Foods and nutrient intakes for all three assessments were calculated using the in-house suites of programmes based on McCance and Widdowson's The Composition of Foods and its Supplements (Prynne et al, 2005).

At the age of 53 years, cohort members were also asked to record any dietary supplements that they consumed each day, and intake of nutrients from supplements was analysed using a newly created supplement database containing 800 dietary supplements frequently consumed in the United Kingdom (McNaughton et al, 2005). Therefore, nutrient intake at this age includes those derived from both food and supplement use. Food and nutrient data on 4 or more days are available for more than $70 \%$ of the cohort members who were contacted at the ages of 36 and 43 years and for $60 \%$ at the age of 53 years. Data on hormone therapy (HT) use and menopausal status were obtained from information on menstrual and HT histories taken from the annual questionnaires sent to the women from the age of 47 to 54 years (Kuh and Hardy, 2003).

In the United Kingdom, all women aged 50-64 years are invited for 3-yearly mammographic screening as part of the National Health Service (NHS) Breast Screening Programme. Thus, copies of the mammograms (two views for each breast) were taken when the women were closest to the age of 50 years, the prevalent screening round, were requested from the relevant centres. Successfully, we obtained the copies of mammograms for 1319 of the 1471 women who gave consent ( $90 \%$ tracing rate), the large majority (1249 (95\%)) from NHS breast screening centres (McCormack et al, 2003). The mammograms were scanned using an Array 2905 laser digitiser with optical density range $0-4.0,12-$ bit depth and pixel size of $75 \mu \mathrm{m}$. Percent mammographic density was measured on the left cranio-caudal view $(n=1014)$ or, if this was not available, on the left medio-lateral oblique view $(n=147)$ using Cumulus, a computer-assisted threshold method (Byng et al, 1994) and calculated as a ratio of the absolute area of dense tissue to the sum of the absolute areas of dense and non-dense tissues. Information on both density and calcium/vitamin D intakes was available for $1161(88 \%)$ women, none of whom were diagnosed with breast cancer at the time of mammogram.

\section{Statistical analysis}

Percent breast density was square root transformed and then standardised. Calcium and vitamin D intakes were categorized using quintiles, intakes were also standardized to express the results in terms of change in percent density per s.d. increase in intake. To assess the combined effects, combinations of groups defined by tertiles of calcium and vitamin $\mathrm{D}$ intakes were formed. Three linear regression models were used to investigate the relationship between percent density and the main exposures of interest, namely intakes of calcium (at the ages of 4, 36, 43 and 53 years), vitamin D (at the ages of 36,43 and 53 years) and their combined effects (at the ages of 36,43 and 53 years), reflecting different levels of adjustment for potential confounding or mediating factors. Other analyses stratified by menopausal status at mammography and separately for the two components of percent breast density: absolute areas of dense (parenchymal) and non-dense (fatty) tissues.

\section{RESULTS}

The mean age of the 1161 women at mammography was 51.5 years. The median (IQR range) for percent mammographic density was $21.9 \%(27.5 \%)$. Mutually adjusted analyses revealed that lower adult social class, earlier menarche, higher parity and higher BMI around the time of mammography were associated with significantly lower percent breast density $(P<0.05$ for each, data not shown). In the multivariate models, quintiles of calcium intake at the age of 4 years, calcium and vitamin D intakes at the ages of 36 ,
43 and 53 years showed no associations with percent breast density (Table 1). There was also no evidence that the level of percent density for women in the top third of both vitamin D and calcium intake distributions was different to the level found among women who were in the bottom third of both distributions. Analyses stratified by menopausal status at the time of mammography showed similar results, except for an inverse association among calcium intake at the age of 53 years, with percent breast density in post-menopausal women such that the mean density was 0.53 s.d. lower (95\% CI: $0.03-1.02$ ) in women in the highest compared with those in the lowest quintile of calcium intake (Table 2). There was, however, no difference in supplement consumption between postand pre-menopausal women of a similar age. Separate analyses for absolute areas of dense and non-dense tissue in the breast found that calcium intake at the age of 53 years was inversely associated $(P$-value for linear trend across quintile groups $=0.06)$ with the absolute area of dense tissue, but positively associated ( $P$-value for linear trend across quintile groups $=0.009$ ) with the area of nondense tissue in women who were post-menopausal at the time of their mammography.

\section{DISCUSSION}

We found no overall associations between calcium and vitamin $\mathrm{D}$ intakes at any age and percent breast density except for a negative association between calcium intake at the age of 53 years and breast density measured around the same age in post-menopausal women only. The lack of evidence reported here between adulthood vitamin D intake and percent breast density is consistent with other studies (Vachon et al, 2000; Thomson et al, 2007). However, other research has suggested that dietary vitamin $\mathrm{D}$ and calcium may be related to mean breast density in premenopausal women (Holmes et al, 2001; Berube et al, 2005; Diorio et al, 2006). In one study, the strength of the negative association between dietary vitamin $\mathrm{D}$ and breast density was found related to the level of calcium intake in pre-menopausal, but not in postmenopausal women (Berube et al, 2005). Unlike earlier studies (Berube et al, 2004, 2005; Knight et al, 2006), no significant associations were detected when we investigated the effect of combined intake of vitamin $\mathrm{D}$ and calcium on percent breast density in either pre- or post-menopausal women.

Sunlight exposure provides most of the body's circulating stores of vitamin D for most people. Individuals with high sunlight exposure and/or high intake of vitamin $\mathrm{D}$ have higher serum levels of $25(\mathrm{OH}) \mathrm{D}$ but, in normal individuals, high serum levels of $25(\mathrm{OH}) \mathrm{D}$ do not result in correspondingly high serum levels of the biologically active form $-1,25(\mathrm{OH})_{2} \mathrm{D}$. However, recent evidence suggests that many organs, including the breast gland, possess $1 \alpha$-hydroxylase activity and thus are able to synthesise $1,25(\mathrm{OH})_{2} \mathrm{D}$ locally from 25(OH)D (Friedrich et al, 2003). Thus, it is conceivable that a diet rich in vitamin $\mathrm{D}$ might reduce breast densities and the risk of breast cancer through an increase in paracrine/autocrine production of $1,25(\mathrm{OH})_{2} \mathrm{D}$.

\section{Explanation of findings}

It is not known which stage in life, if any, is the most relevant time period during which dietary intake influences breast densities in later life, but there was low tracking of childhood calcium intake into adulthood. The Spearman correlation coefficients between childhood and adulthood calcium intakes ranged from 0.02 (at the age of 36 years) to 0.06 (at the age of 53 years), suggesting that the nutrient intake patterns have changed over time.

The observed association between calcium intake and breast density may be spurious as it was restricted to intake at the age of 53 years and to women who were post-menopausal; thus, suggesting that the calcium intake may be a proxy for changes 
Table I Adjusted regression coefficient ${ }^{\mathrm{a}}$ (95\% confidence intervals) for percent breast density by dietary calcium and vitamin D intakes at various ages

\begin{tabular}{lcc}
\hline & & \\
& $\mathbf{N}$ & $\begin{array}{c}\text { Median perce } \\
\text { breast density } \\
(\mathbf{I Q R})^{\mathbf{b}}\end{array}$ \\
\hline $\begin{array}{l}\text { Age 4 years }(n=979) \\
\text { Calcium intake }\left(\mathrm{mg} \mathrm{day}^{-1}\right)\end{array}$ & & \\
$\quad \leqslant 538$ & 186 & $18.8(25.4)$ \\
$539-661$ & 199 & $20.9(27.7)$ \\
$662-777$ & 198 & $22.6(28.2)$ \\
$778-912$ & 184 & $24.0(25.3)$ \\
$\geqslant 913$ & 212 & $21.6(31.4)$
\end{tabular}

$P$-value for linear trend

Per I s.d. increase in calcium intake

Age 36 years $(n=766)$

Calcium intake $\left(\mathrm{mg} \mathrm{day}^{-1}\right)$ $\leqslant 523$

$524-648$

$652-784$

$785-940$

$\geqslant 941$

$P$-value for linear trend

Per I s.d. increase in calcium intake

Vitamin D intake $\left(\mu \mathrm{g} \mathrm{day}^{-1}\right)$

$\leqslant 1.052$

$1.053-1.581$

$1.582-2.192$

$2.193-3.18$

$\geqslant 3.19$

$P$-value for linear trend

Per I s.d. increase in vitamin D intake

Age 43 years $(n=755)$

Calcium intake $\left(\mathrm{mg} \mathrm{day}^{-1}\right)$

$\leqslant 611$

$612-735$

$736-859$

$860-1020$

$\geqslant 1021$

$P$-value for linear trend

Per I s.d. increase in calcium intake

Vitamin D intake $\left(\mu \mathrm{g} \mathrm{day}^{-1}\right)$

$$
\begin{aligned}
& \leqslant 1.510 \\
& 1.511-2.234 \\
& 2.235-3.019 \\
& 3.020-4.125
\end{aligned}
$$

$\geqslant 4.126$

P-value for linear trend

Per I s.d. increase in vitamin $D$ intake

Age 53 years $(n=674)$

Calcium intake (mg day ${ }^{-1}$

$$
\leqslant 699
$$

$700-846$

$847-976$

$977-1179$

$\geqslant 1180$

$P$-value for linear trend

Per I s.d. increase in calcium intake

Vitamin D intake $\left(\mu \mathrm{gday}^{-1}\right)$

$$
\begin{aligned}
& \leqslant 2.198 \\
& 2.199-3.118 \\
& 3.119-4.702
\end{aligned}
$$

$25.9(26.5)$

$26.2(27.4)$

$19.3(22.8)$

$26.4(28.8)$

$19.4(24.2)$

$30.0(28.7)$

$19.3(29.4)$

$18.6(25.6)$

$22.5(30.3)$

$29.1(28.4)$

$23.1(27.0)$

$22.5(29.3)$

$21.9(23.9)$

$24.3(28.2)$

$23.4(25.2)$

$22.4(26.6)$

$23.3(29.9)$

$24.0(26.5)$

$22.8(25.8)$

$20.2(25.5)$
Model I: adjusted for age at mammography, mammographic view, total energy intake and BMI at the age of 53 years ${ }^{c}$
Model 2: further adjusted for reproductive and lifestyle factors ${ }^{c}$
Model 3: further adjusted for eithe calcium or vitamin D intakes as appropriate $^{c}$

$$
\begin{gathered}
\text { Reference } \\
0.16(-0.02,0.35) \\
0.11(-0.08,0.31) \\
0.16(-0.05,0.36) \\
0.12(-0.10,0.34) \\
0.4 \\
0.03(-0.05,0.10)
\end{gathered}
$$

$-0.002(-0.08,0.07)$
Reference

$-0.06(-0.28,0.15)$

$0.01(-0.21,0.23)$

$0.05(-0.18,0.28)$

$0.00(-0.25,0.24)$ 0.7

$0.001(-0.08,0.08)$

Reference

$0.18(-0.02,0.39)$

$-0.10(-0.31,0.10)$

$0.27(0.07,0.48)$

$-0.04(-0.25,0.17)$ 0.9

$-0.03(-0.09,0.04)$

$.06(-0.28,0.15)$

$0.06(-0.16,0.29)$

$0.03(-0.20,0.25)$

$-0.09(-0.34,0.15)$

0.8

$-0.02(-0.11,0.06)$

Reference

$0.05(-0.16,0.26)$

$-0.04(-0.25,0.18)$

$-0.08(-0.29,0.14)$

$-0.02(-0.25,0.20)$

0.5

$-0.03(-0.10,0.04)$

Reference

$0.06(-0.17,0.29)$

$0.01(-0.22,0.25)$

$-0.13(-0.37,0.11)$

$-0.02(-0.27,0.22)$

0.4

Reference $-0.06(-0.28,0.15)$ $-0.05(-0.28,0.17)$
Reference

$-0.11(-0.32,0.11)$

$-0.03(-0.25,0.19)$

$-0.01(-0.24,0.22)$

$-0.06(-0.31,0.19)$ 0.9

$-0.01(-0.09,0.07)$

Reference

$0.17(-0.04,0.37)$

$-0.10(-0.31,0.10)$

$0.24(0.03,0.44)$

$-0.07(-0.28,0.14)$ 0.7

$-0.03(-0.09,0.03)$

Reference

$-0.15(-0.36,0.07)$

$-0.08(-0.30,0.14)$

$-0.12(-0.35,0.11)$

$-0.18(-0.44,0.07)$ 0.3

$-0.05(-0.13,0.03)$

Reference

$0.05(-0.16,0.26)$

$-0.08(-0.30,0.13)$

$-0.12(-0.33,0.09)$

$-0.09(-0.31,0.13)$

0.16

$-0.04(-0.11,0.03)$

Reference

$0.02(-0.21,0.24)$

$-0.01(-0.24,0.22)$

$-0.16(-0.40,0.08)$

$-0.08(-0.33,0.17)$

$$
0.2
$$

$-0.02(-0.09,0.06)$

Reference

Reference

$-0.11(-0.33,0.10)$

$-0.05(-0.27,0.17)$

$-0.04(-0.27,0.19)$

$-0.08(-0.32,0.17)$

0.9

$-0.01(-0.09,0.07)$

Reference

$0.17(-0.03,0.38)$

$-0.10(-0.30,0.11)$

$0.24(0.03,0.45)$

$-0.07(-0.28,0.15)$

0.7

$-0.03(-0.09,0.03)$

Reference

$-0.13(-0.35,0.09)$

$-0.06(-0.29,0.17)$

$-0.11(-0.34,0.12)$

$-0.16(-0.42,0.09)$

0.4

$-0.05(-0.13,0.04)$

Reference

$0.07(-0.14,0.28)$

$-0.06(-0.28,0.17)$

$-0.09(-0.31,0.13)$

$-0.06(-0.29,0.17)$

0.2

$-0.04(-0.10,0.03)$

$-0.08(-0.30,0.14)$

$-0.05(-0.27,0.17)$
Reference

$0.02(-0.21,0.25)$

$-0.01(-0.24,0.22)$

$-0.16(-0.40,0.08)$

$-0.09(-0.34,0.17)$

0.2

$-0.02(-0.10,0.05)$

Reference

$-0.07(-0.29,0.15)$

$-0.04(-0.26,0.19)$ 
Table I (Continued)

\begin{tabular}{|c|c|c|c|c|c|}
\hline & $\mathbf{N}$ & $\begin{array}{l}\text { Median percent } \\
\text { breast density } \\
(\text { IQR })^{\mathbf{b}}\end{array}$ & $\begin{array}{l}\text { Model I: adjusted for age at } \\
\text { mammography, mammographic } \\
\text { view, total energy intake and } \\
\text { BMI at the age of } 53 \text { years }{ }^{c}\end{array}$ & $\begin{array}{l}\text { Model 2: further } \\
\text { adjusted for } \\
\text { reproductive and } \\
\text { lifestyle factors }{ }^{c}\end{array}$ & $\begin{array}{c}\text { Model 3: further } \\
\text { adjusted for either } \\
\text { calcium or vitamin } D \\
\text { intakes as appropriate }\end{array}$ \\
\hline
\end{tabular}

${ }^{a}$ Regression coefficient from the regression models can be interpreted as the number of s.d. difference in percent breast density between each quintile of calcium and vitamin $D$ and the reference category. ' Inter-quartile range. 'Adjustments were carried out for mammographic view (cranio-caudal and medio-lateral oblique), age at the time of mammogram (continuous), BMI at the age of 53 years (continuous), total energy intake (continuous), age at menarche (<12, 12, I3 and I4+ years), menopausal status at the time of mammography (pre-, peri-, post-, hysterectomy), hormone therapy use (current or ever), parity (0, I, 2, 3 and 4+), smoking status (current smoker and non-smoker) and social class during adult life (non-manual and manual).

Table 2 Regression coefficient ${ }^{\mathrm{a}}$ (95\% confidence intervals) for percent breast density by calcium and vitamin D intake at the age of 53 years separately for pre-menopausal and post-menopausal women at the time of mammography ${ }^{b}$

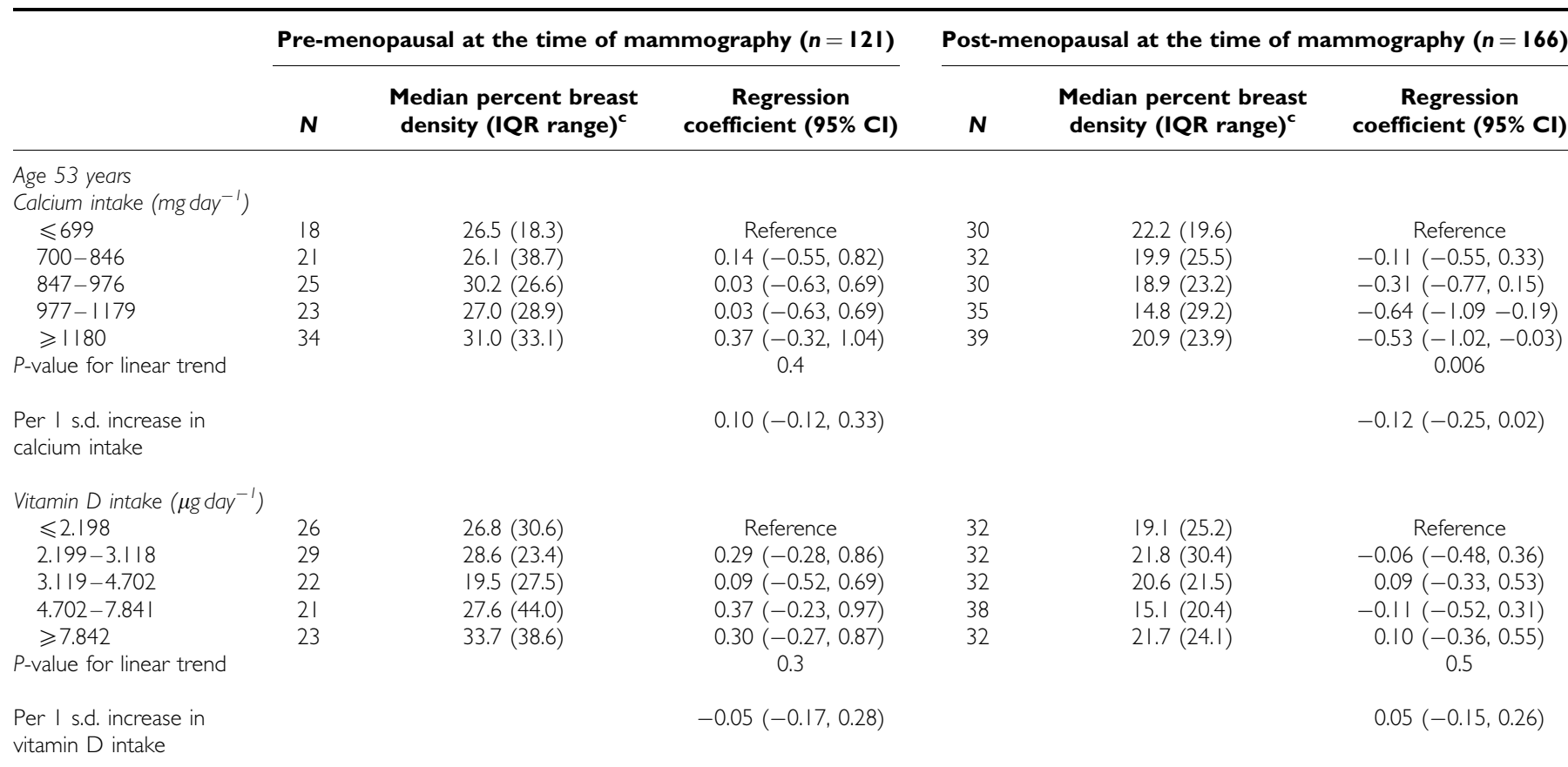

${ }^{a}$ Adjusted for mammographic view (cranio-caudal and medio-lateral oblique), age at the time of mammogram (continuous), BMl at the age of 53 years (continuous), total energy intake (continuous), age at menarche ( $<12,12,13$ and 14+ years), parity $(0,1,2,3$ and $4+$ ), smoking status (current smoker and non-smoker) and social class during adult life (non-manual and manual). ' Excludes women who were peri-menopausal $(n=120)$, underwent a surgical menopause $(n=1 \mid$ 6), on HT (I39) or whose menopausal status was unknown $(n=12)$. Inter-quartile range.

in health behaviours in response to menopause. As women in this cohort were all of the same age, post-menopausal women were only slightly older at the time of mammographic screening. The mean age at mammographic screening was 51.3 years $($ s.d. $=0.9)$ for pre-menopausal women compared with 51.9 years $($ s.d. $=1.1)$ for post-menopausal women. Therefore, given an average of 6-months age difference between the pre- and post-menopausal women, it was unlikely that the age of post-menopausal women at the time of mammographic screening explained the inverse findings. Furthermore, the inverse association between calcium intake and percent density reflected mainly a positive effect of calcium intake on the non-dense (fatty) tissue, although a weaker negative effect on the dense (parenchymal) tissue was also observed. As a majority of the women (54\%) had mammograms taken within 2 years before the recording of dietary intakes at the age of 53 years, their dietary intakes may have changed post-screening.
It is also possible that calcium and vitamin $\mathrm{D}$ intakes are not associated with breast density at the age of which the mammograms were taken. The range of variation in intakes and/or breast density in the study population might have been too narrow to allow detection of any potential associations. The difference in food fortification practices and supplement use between North America and the United Kingdom, and therefore the different level of calcium and vitamin D intakes (Scientific Advisory Committee on Nutrition, 2007) may explain in part the disparity in the results among studies. Finally, any potential effects of calcium and vitamin $\mathrm{D}$ levels on breast density may be modulated by genetic and other constitutional traits, with only a small proportion of women being susceptible to such effects.

This study concerns one of the few cohorts with measures of diet collected in childhood and with repeated measures throughout adult life. Dietary intakes in adulthood were based on 5-day food diaries rather than FFQ, which resulted in higher precision of 
estimates, and we adjusted for a range of potential confounding and/or mediating variates. Sample size for the analyses ranged from 674 to 979 women, depending on the age, at which the data were collected. Therefore, our study had a power of $80 \%$ to detect, at the $5 \%$ significance level, a maximum difference of 0.1 s.d. of the square root-transformed percentage densities, using linear regression models.

The single 24-h recalls, used at the age of 4 years, are not generally considered to be reflective of usual intake and not the preferred dietary assessment method for associations with health or disease outcomes. However, the diets in the 1950s were much less variable than in more recent times, and a dietary pattern shown for 1 day is likely to be repeated throughout the week, particularly for major foods, such as fruits and vegetables, meat, milk and so on (Prynne et al, 2002). We have already shown these dietary data are robust enough for epidemiologic studies, when used either to compare group means or with rank subjects according to the levels of food consumption or nutrient intake (Mishra et al, 2003).

Multiple assessments of dietary intake during adulthood were used rather than a single assessment, and period-specific food composition databases were used to calculate the intakes allowing for real changes in food composition over time to be incorporated into the exposure measurement (Prynne et al, 2005). Percent density

\section{REFERENCES}

Berube S, Diorio C, Masse B, Hebert-Croteau N, Byrne C, Cote G, Pollak M, Yaffe M, Brisson J (2005) Vitamin D and calcium intakes from food or supplements and mammographic breast density. Cancer Epidemiol Biomarkers Prev 14: $1653-1659$

Berube S, Diorio C, Verhoek-Oftedahl W, Brisson J (2004) Vitamin D, calcium, and mammographic breast densities. Cancer Epidemiol Biomarkers Prev 13: 1466-1472

Byng JW, Boyd NF, Fishell E, Jong RA, Yaffe MJ (1994) The quantitative analysis of mammographic densities. Phys Med Biol 39: 1629-1638

Cui Y, Rohan TE (2006) Vitamin D, calcium, and breast cancer risk: a review. Cancer Epidemiol Biomarkers Prev 15: 1427-1437

Diorio C, Berube S, Byrne C, Masse B, Hebert-Croteau N, Yaffe M, Cote G, Pollak M, Brisson J (2006) Influence of insulin-like growth factors on the strength of the relation of vitamin $\mathrm{D}$ and calcium intakes to mammographic breast density. Cancer Res 66: 588-597

dos Santos Silva I, De Stavola B (2002) Breast cancer aetiology: where do we go from here?. In A life course approach to women's health, Kuh D, Hardy R (eds), pp 44-63. Oxford University Press: Oxford

dos Santos Silva I, De Stavola BL, Hardy RJ, Kuh DJ, McCormack VA, Wadsworth ME (2004) Is the association of birth weight with premenopausal breast cancer risk mediated through childhood growth? Br J Cancer 91: 519-524

Friedrich M, Rafi L, Mitschele T, Tilgen W, Schmidt W, Reichrath J (2003) Analysis of the vitamin D system in cervical carcinomas, breast cancer and ovarian cancer. Recent Results Cancer Res 164: 239-246

Garland CF, Gorham ED, Mohr SB, Grant WB, Giovannucci EL, Lipkin M, Newmark H, Holick MF, Garland FC (2007) Vitamin D and prevention of breast cancer: pooled analysis. J Steroid Biochem Mol Biol 103: $708-711$

Holmes MD, Hankinson SE, Bryne C (2001) Mammographic density and diet. Am J Epidemiol 153: S109

John EM, Schwartz GG, Koo J, Wang W, Ingles SA (2007) Sun Exposure, Vitamin D Receptor Gene Polymorphisms, and Breast Cancer Risk in a Multiethnic Population. Am J Epidemiol 166: 1409-1419

Knight JA, Vachon CM, Vierkant RA, Vieth R, Cerhan JR, Sellers TA (2006) No association between 25-hydroxyvitamin D and mammographic density. Cancer Epidemiol Biomarkers Prev 15: 1988-1992

Kuh D, Hardy R (2003) Women's health in midlife: findings from a British birth cohort study. J Br Menopause Soc 9: 55-60

McCormack VA, dos Santos Silva I (2006) Breast density and parenchymal patterns as markers of breast cancer risk: a meta-analysis. Cancer Epidemiol Biomarkers Prev 15: 1159-1169 readings were highly repeatable (90 films were independently and blindly reread, giving an intra-class correlation coefficient of $0.91,95 \%$ CI: $0.89,0.93$ ), and relationships with the established determinants of density (e.g. BMI, menopausal status and HT use) were observed, giving weight to the validity of the outcome data.

In summary, this study found no evidence for long-term effects of calcium and vitamin $\mathrm{D}$ intakes on breast density at the mean age of 51 years. Considering the biological plausibility of an association between calcium and vitamin $\mathrm{D}$ and breast cancer risk, further cohort investigations are warranted with the repeated assesments throughout life of calcium and vitamin D intakes, sun exposure and serum 25(OH)D levels in relation to percent breast density and absolute areas of dense and non-dense tissues.

\section{ACKNOWLEDGEMENTS}

Breast Cancer Campaign UK-World Cancer Research Fund International and the Medical Research Council fund this project. ISS and VM are members of the Cancer Research UK Epidemiology and Genetics Group; VM is funded by a Cancer Research UK training fellowship.
McCormack VA, dos Santos Silva I, De Stavola BL, Perry N, Vinnicombe S, Swerdlow AJ, Hardy R, Kuh D (2003) Life-course body size and perimenopausal mammographic parenchymal patterns in the MRC 1946 British birth cohort. Br J Cancer 89: 852-859

McNaughton SA, Mishra GD, Paul AA, Prynne CJ, Wadsworth ME (2005) Supplement use is associated with health status and health-related behaviors in the 1946 British birth cohort. J Nutr 135: 1782-1789

Mishra GD, Malik NS, Paul AA, Wadsworth ME, Bolton-Smith C (2003) Childhood and adult dietary vitamin $\mathrm{E}$ intake and cardiovascular risk factors in mid-life in the 1946 British Birth Cohort. Eur J Clin Nutr 57: $1418-1425$

Prynne CJ, Paul AA, Mishra GD, Greenberg DC, Wadsworth ME (2005) Changes in intake of key nutrients over 17 years during adult life of a British birth cohort. Br J Nutr 94: 368-376

Prynne CJ, Paul AA, Mishra GD, Hardy RJ, Bolton-Smith C, Wadsworth ME (2002) Sociodemographic inequalities in the diet of young children in the 1946 British birth cohort. Public Health Nutr 5: 733-745

Scientific Advisory Committee on Nutrition (2007) Update on Vitamin D. The Stationary Office: London

Sellers TA, Vachon CM, Pankratz VS, Janney CA, Fredericksen Z, Brandt KR, Huang Y, Couch FJ, Kushi LH, Cerhan JR (2007) Association of childhood and adolescent anthropometric factors, physical activity, and diet with adult mammographic breast density. Am J Epidemiol 166: 456-464

Shin MH, Holmes MD, Hankinson SE, Wu K, Colditz GA, Willett WC (2002) Intake of dairy products, calcium, and vitamin d and risk of breast cancer. J Natl Cancer Inst 94: 1301-1311

Thomson CA, Arendell LA, Bruhn RL, Maskarinec G, Lopez AM, Wright NC, Moll CE, Aickin M, Chen Z (2007) Pilot study of dietary influences on mammographic density in pre- and postmenopausal Hispanic and non-Hispanic white women. Menopause 14: 243-250

Vachon CM, Kushi LH, Cerhan JR, Kuni CC, Sellers TA (2000) Association of diet and mammographic breast density in the Minnesota breast cancer family cohort. Cancer Epidemiol Biomarkers Prev 9: 151-160

Wadsworth M, Kuh D, Richards M, Hardy R (2006) Cohort Profile: The 1946 National Birth Cohort (MRC National Survey of Health and Development). Int J Epidemiol 35: 49-54

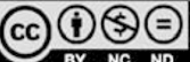

This work is licensed under the Creative Commons Attribution-NonCommercial-NoDerivs 3.0 License. To view a copy of this license, visit http://creativecommons.org/ licenses/by-nc-nd/3.0/. 